\title{
Burnout and Health Care Workforce Turnover
}

Rachel Willard-Grace, MPH

Margae Knox, $\mathrm{MPH}^{1}$

Beatrice Huang, $B A^{1}$

Hali Hammer, $M D^{2}$

Coleen Kivlaban, MD, MSPH

Kevin Grumbach, $M D^{1}$

'Department of Family \& Community Medicine, University of California San Francisco, San Francisco, California

${ }^{2}$ San Francisco Health Network, San Francisco, California

${ }^{3}$ University of California San Francisco School of Medicine, San Francisco, California

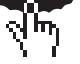

MORE ONLINE

www.annfammed.org
Conflicts of interest: authors report none.

\section{CORRESPONDING AUTHOR}

Rachel Willard-Grace, MPH

Department of Family \& Community

Medicine

University of California San Francisco

1001 Potrero Ave, Ward 83

San Francisco, CA 94110

Rachel.Willard@ucsf.edu

\begin{abstract}
PURPOSE Levels of burnout among primary care clinicians and staff are alarmingly high, and there is widespread belief that burnout and lack of employee engagement contribute to high turnover of the workforce. Scant research evidence exists to support this assertion, however.
\end{abstract}

METHODS We conducted a longitudinal cohort study using survey data on burnout and employee engagement collected in 2013 and 2014 from 740 primary care clinicians and staff in 2 San Francisco health systems, matched to employment roster data from 2016.

RESULTS Prevalence of burnout, low engagement, and turnover were high, with $53 \%$ of both clinicians and staff reporting burnout, only $32 \%$ of clinicians and $35 \%$ of staff reporting high engagement, and $30 \%$ of clinicians and $41 \%$ of staff no longer working in primary care in the same system 2 to 3 years later. Burnout predicted clinician turnover (adjusted odds ratio $=1.57 ; 95 \% \mathrm{Cl}, 1.02-2.40$ ); there was also a strong trend whereby low engagement predicted clinician turnover (adjusted odds ratio with high engagement $=0.58 ; 95 \% \mathrm{Cl}, 0.33-1.04$ ). Neither measure significantly predicted turnover for staff.

CONCLUSIONS High rates of burnout and turnover in primary care are compelling problems. Our findings provide evidence that burnout contributes to turnover among primary care clinicians, but not among staff. Although reducing clinician burnout may help to decrease rates of turnover, health care organizations and policymakers concerned about employee turnover in primary care need to understand the multifactorial causes of turnover to develop effective retention strategies for clinicians and staff.

Ann Fam Med 2019;17:36-41. https://doi.org/10.1370/afm.2338.

\section{INTRODUCTION}

$\mathrm{P}$ rimary care physicians have among the highest rates of burnout among physician specialties, with more than $60 \%$ of those in the United States reporting high levels of burnout as measured by a commonly used scale. ${ }^{1}$ National health care goals have expanded to include the concept of the quadruple aim, with a proposed fourth aim being sustainability of practice for clinicians and staff. 2,3 The American Medical Association's establishment of the STEPS Forward program to promote joy in practice reflects the growing effort by professional organizations, health care systems, and other stakeholders to reduce burnout in hopes of advancing the quadruple aim. ${ }^{4}$

Burnout is a problem in its own right for reasons of concern about the well-being of health care workers. There is also concern that burnout and low engagement in the workplace may adversely affect patient care, destabilize the workforce, and increase turnover. ${ }^{5}$ Turnover may have a cost in terms of both the interruption in continuity-of-care relationships and the high expense associated with recruiting new clinicians and staff. ${ }^{6,7}$

An association between burnout and low engagement with employee turnover is plausible and frequently asserted. ${ }^{6}$ Publications and promotional materials for the most commonly used measures of burnout and employee engagement avow their ability to predict and influence turnover. ${ }^{8}$ Surprisingly, however, little research has been performed on this 
topic in primary care, and existing research does not provide particularly strong evidence in support of these hypothesized relationships. Most research has relied on declared intention to leave as a proxy for turnover, rather than longitudinally tracking actual turnover behavior, ${ }^{9}$ but intention to leave is not a reliable predictor of attrition. ${ }^{10}$ One recent study at the Mayo Clinic found that higher burnout among physicians in diverse specialties predicted a reduction in work hours 1 year later, but did not report on turnover. ${ }^{11}$ Some studies have found an association between physician or nurse satisfaction and turnover ${ }^{12-14}$ or reduction in work hours, ${ }^{15}$ but this research has not included validated burnout scales as predictors. A recently published research letter showed an association among physicians in diverse specialties at the Cleveland Clinic between burnout and the likelihood of leaving the organization ${ }^{16}$; this is the only published study we could identify in the past 20 years that used formal burnout measures as predictors and actual turnover as the outcome. Similarly, there is a paucity of published research on the degree to which commonly used measures of employee engagement, such as recommending the organization as a place to work, are associated with meaningful outcomes such as employee turnover.

The growing attention to burnout and employee engagement in health care must be matched by better evidence about how burnout affects the workforce, patient care, and health care organizations. ${ }^{6}$ We conducted a study in 2 health care organizations to determine whether high levels of burnout and low employee engagement predicted turnover among primary care workers 2 to 3 years later.

\section{METHODS}

This longitudinal cohort study used survey data collected in 2013 and 2014 from primary care clinicians and staff in 2 San Francisco health systems, matched to employment roster data from 2016. The study protocol was approved by the University of California, San Francisco Committee on Human Research (11-08048).

\section{Setting and Participants}

We surveyed all physicians, other clinicians, and staff working in primary care clinics operated by a university health system (6 clinics) and a county health department (10 clinics) in San Francisco. Surveys are conducted on an annual basis in each system by a center that is external to the leadership and human resource structures of both systems; clinic and system leaders receive aggregate responses but do not have access to individual responses. We used data from the
2013 and 2014 survey waves for this study. All clinic personnel are employees of their respective systems. Resident physicians and fellows take part in the survey but were excluded from the respondent population used in this study because of their expected turnover after completing training.

\section{Measures}

Survey measures included 2 subscales from the Maslach Burnout Inventory (MBI) General Survey: the 5-item emotional exhaustion subscale and the 5 -item cynicism subscale. Each subscale produces a total score ranging from 0 to 30, where 30 is the highest level of exhaustion or cynicism. Thresholds of 16 and 11 are standard markers for high exhaustion and cynicism, respectively. ${ }^{7}$ As has been done in other health care studies, we classified respondents as having burnout if they scored highly on either subscale. ${ }^{17,18}$

We also included a commonly used measure of employee engagement, the "friends and family" question, used to create the net promoter score, which asks about the likelihood that the respondent would recommend their clinic as a place to work (scale of 0 to 10). ${ }^{19}$ The conventional net promoter score approach classifies respondents with scores of 9 and 10 as promoters, 7 and 8 as passively satisfied, and 6 or lower as detractors. The survey also collected data on part- vs full-time status (for staff), number of half-days of clinic per week (for clinicians), and tenure of employment.

For this analysis, we defined clinicians as physicians, nurse practitioners, and physician assistants who manage a continuity patient panel. Staff included medical assistants, registered nurses, front office administrative personnel, and behavioral health professionals such as social workers. If respondents answered the survey in both 2013 and 2014, we used their 2013 responses to optimize the length of follow-up time for the study.

We matched respondents to the 2013 and 2014 waves of the survey with rosters in 2016 of current workers at these same clinics obtained from medical and administrative directors at each clinic. Roster data for 2016 were verified by system administrators before final data analyses to confirm the accuracy of worker status. We defined turnover for staff as no longer working at any primary care clinic in the respective system, and for clinicians as no longer working in a primary care continuity clinical role at any clinic in the system (ie, caring for their own panel of primary care patients). For example, a clinician who moved a continuity practice from one clinic to another in the same system was not defined as having turned over, but a clinician who moved into a non-patient care role in the system or left the system entirely was considered as having turned over. 


\section{Analysis}

Data analysis was conducted using Stata version 13

(StataCorp LP). As done in prior literature, ${ }^{17,18}$ we used burnout as a dichotomous variable. Similarly, because of conventions used for calculating a net promoter score from the employee engagement item ${ }^{19}$ and the skewed distribution of scores, we treated this item as a dichotomous variable, categorizing respondents as highly engaged ("promoters" with scores of 9 or 10) vs all others (8 or lower). We examined bivariate associations between the predictor variables and turnover, comparing rates of turnover in each group using $\chi^{2}$ analysis. We then performed logistic regression modeling, stratified by clinicians and staff, with turnover as the outcome $(0=$ still in the system; $1=$ left the system). We ran separate regression models for each predictor variable (burnout and employee engagement). Covariates in all models included years at the site, part- vs full-time status (for staff), number of half-days of clinic per week (for clinicians), system, and survey year, with adjustment of standard errors for clustering of respondents at the clinic level. Because of potential differences in experiences of physicians and advanced practice clinicians (nurse practitioners and physician assistants), we ran the models separately for each group to compare the pattern of results. The Hosmer Lemeshow goodness of fit test was performed for each model.

We estimated statistical power for detecting a significant association between burnout and turnover based on the dichotomous measure of burnout. Using an interclass correlation statistic adjusted for clustering at the clinic level, we determined that we had $80 \%$ power with an $\alpha$ of .05 to detect a relative difference of $20 \%$ for clinicians and $13 \%$ for staff in turnover rates between workers with burnout and those without.

\section{RESULTS}

A total of 252 clinicians and 488 staff responded to at least 1 survey wave in 2013 or 2014 and met study eligibility criteria (Table 1). The response rate was $90 \%$ in each year, with clinician response rate ranging from $85 \%$ to $89 \%$ and staff response rate from $91 \%$ to $94 \%$ across the
2 years. More than one-half of clinicians (53\%) and more than one-third of staff (40\%) reported having worked at their clinic for longer than 5 years. About two-thirds responded to the survey in 2013, with the remainder responding only in 2014.
Table 1. Respondent Characteristics $(N=740)$

\begin{tabular}{|c|c|c|}
\hline Characteristic & $\begin{array}{l}\text { Clinicians } \\
(n=252)\end{array}$ & $\begin{array}{c}\text { Staff } \\
(n=488)\end{array}$ \\
\hline \multicolumn{3}{|l|}{ Position, \% (No.) } \\
\hline Physician (nonresident) & $79.0(199)$ & - \\
\hline Nurse practitioner/Physician assistant & $21.0(53)$ & - \\
\hline Nurse (RN or LVN) & - & $21.7(106)$ \\
\hline Medical assistant & - & $30.9(151)$ \\
\hline Front office/clerical & - & $25.2(123)$ \\
\hline Behavioral health & - & $8.4(41)$ \\
\hline Other & - & $13.7(67)$ \\
\hline \multicolumn{3}{|l|}{ Tenure at time of survey, \% (No.) } \\
\hline$<1$ year & $16.8(42)$ & $22.8(111)$ \\
\hline $1-5$ years & $30.0(75)$ & $36.8(179)$ \\
\hline$>5$ years & $53.2(133)$ & $40.3(196)$ \\
\hline \multicolumn{3}{|l|}{ Full- vs part-time (staff only), \% (No.) } \\
\hline Full-time ( $\geq 20$ hours/week) & - & $91.9(445)$ \\
\hline Part-time (<20 hours/week) & - & $8.1(39)$ \\
\hline \multicolumn{3}{|l|}{$\begin{array}{l}\text { Half-days worked per week, (clinicians } \\
\text { only), \% (No.) }\end{array}$} \\
\hline 1-2 half-days/wk & $37.9(94)$ & - \\
\hline 3-5 half-days/wk & $37.5(93)$ & - \\
\hline$\geq 6$ half-days/wk & $24.6(61)$ & - \\
\hline \multicolumn{3}{|l|}{ Year of survey, \% (No.) } \\
\hline 2013 & $73.0(184)$ & $60.7(296)$ \\
\hline 2014 & $27.0(68)$ & $39.3(192)$ \\
\hline Burned out, b \% (No./No. responding) & $53.2(132 / 248)$ & $52.8(249 / 472)$ \\
\hline \multicolumn{3}{|l|}{ MBI emotional exhaustion ${ }^{c}$} \\
\hline Exhaustion score, mean (SD) & $15.3(7.4)$ & $13.8(8.2)$ \\
\hline Low exhaustion (0-10), \% (No.) & $29.2(72)$ & $38.0(180)$ \\
\hline Moderate exhaustion (11-15), \% (No.) & $23.1(57)$ & $17.9(85)$ \\
\hline High exhaustion ( $\geq 16$ ), \% (No.) & $47.8(118)$ & $44.1(209)$ \\
\hline \multicolumn{3}{|l|}{$\mathrm{MBI}$ cynicism } \\
\hline Cynicism score, mean (SD) & $8.8(6.9)$ & $8.3(7.2)$ \\
\hline Low cynicism (0-5), \% (No.) & $39.1(97)$ & $45.2(212)$ \\
\hline Moderate cynicism (6-10), \% (No.) & $27.8(69)$ & $20.7(97)$ \\
\hline High cynicism ( $\geq 11), \%$ (No.) & $33.1(82)$ & $34.1(160)$ \\
\hline \multicolumn{3}{|l|}{$\begin{array}{l}\text { Engagement: likelihood to recommend clinic } \\
\text { as a place to work }\end{array}$} \\
\hline Net promoter score, mean (SD) & $6.9(2.5)$ & $6.9(2.7)$ \\
\hline Detractor (0-6), \% (No.) & $36.0(89)$ & $36.7(172)$ \\
\hline Passively satisfied (7-8), \% (No.) & $32.0(79)$ & $28.8(135)$ \\
\hline Promoter (9-10), \% (No.) & $32.0(79)$ & $34.5(162)$ \\
\hline Turnover, \% (No.) & $30.2(76)$ & $41.2(201)$ \\
\hline \multicolumn{3}{|c|}{ 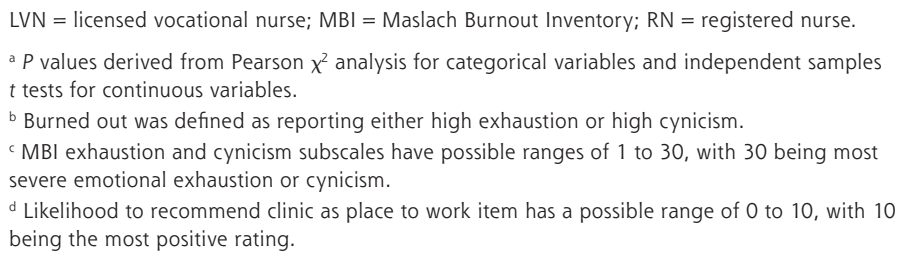 } \\
\hline
\end{tabular}


Figure 1. Rates of turnover among clinicians and staff with and without burnout, unadjusted for covariates and clustering.

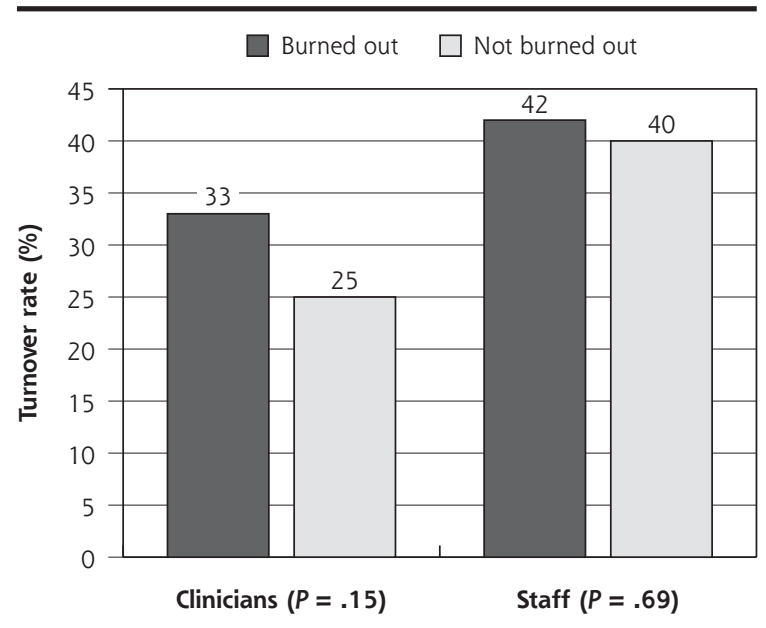

Note: Respondents were categorized as burned out if they reported either high exhaustion or high cynicism on the Maslach Burnout Inventory.
Figure 2. Rates of turnover among clinicians and staff according to level of employee engagement, unadjusted for covariates and clustering.

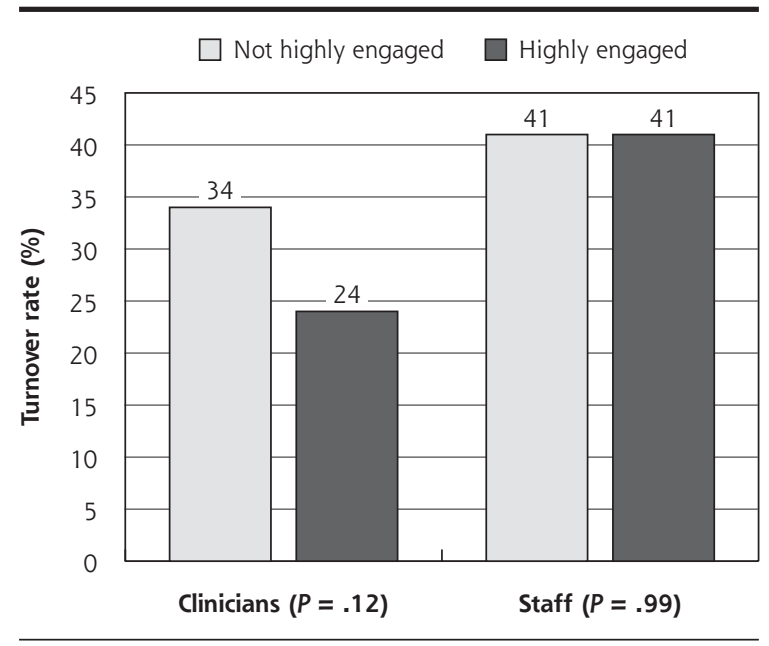

Note: Engagement was assessed with net promotor score. Scores dichotomized to highly engaged (promoters, score of 9 or 10) and not highly engaged (passively satisfied or detractors, score of 0 to 8 ).
Slightly more than one-half of respondents $(53 \%$ for both clinicians and staff) had burnout (Table 1). On the employee engagement item, $32 \%$ of clinicians and $35 \%$ of staff were classified as highly engaged (promoters), with a score of 9 or 10 on the 10-point scale Turnover among respondents was high, with $30 \%$ of clinicians and $41 \%$ of staff no longer working in primary care in the same system 2 to 3 years later.

In bivariate analysis, there was a nonsignificant trend for clinicians with burnout to have a higher rate of turnover (turnover rate 33\% among clinicians with burnout vs $25 \%$ without burnout, $P=.15$ ) (Figure 1). This trend was also present using employee engagement as the predictor (turnover rate of $34 \%$ for clinicians not highly engaged vs $24 \%$ for those highly engaged, $P=.12$ ) (Figure 2 ). In contrast, for staff, rates of turnover were virtually the same among those with vs without burnout ( $42 \%$ vs $40 \%$ ) and those who were vs were not highly engaged ( $41 \%$ for each) (Figures 1 and 2).

In logistic regression models controlling for factors such as health system and tenure at the clinic, burnout was a significant predictor of turnover for clinicians (adjusted odds ratio $[\mathrm{aOR}]=1.57 ; 95 \% \mathrm{CI}, 1.02-2.40$ ) (Table 2). When individual subscales of the MBI were examined, the cynicism subscale score was a significant predictor of turnover for clinicians $(\mathrm{aOR}=1.04$ for each 1-point increase in the cynicism scale; $95 \% \mathrm{CI}, 1.01$ 1.07), but the exhaustion subscale score
Table 2. Multivariate Models of Burnout and Employee Engagement as Predictors of Turnover

\begin{tabular}{|c|c|c|c|}
\hline Group and Predictor & $\begin{array}{l}\text { aOR }(95 \% \mathrm{CI}) \\
\text { for Turnover }\end{array}$ & $\begin{array}{c}\text { Robust } \\
\text { Standard Error }\end{array}$ & $\begin{array}{c}P \\
\text { Value }\end{array}$ \\
\hline \multicolumn{4}{|l|}{ Clinicians ( $n=242$ to 244 ) } \\
\hline Burned out & $1.57(1.02-2.40)$ & 0.34 & .04 \\
\hline Highly engaged & $0.58(0.33-1.04)$ & 0.17 & .07 \\
\hline \multicolumn{4}{|l|}{ Staff $(n=464$ to 468$)$} \\
\hline Burned out & $1.09(0.66-1.82)$ & 0.28 & .73 \\
\hline Highly engaged & $0.99(0.57-1.71)$ & 0.28 & .96 \\
\hline \multicolumn{4}{|l|}{ aOR = adjusted odds ratio. } \\
\hline \multicolumn{4}{|c|}{$\begin{array}{l}\text { Notes: Results of multivariate logistic regression analysis. Four multivariate regression mod- } \\
\text { els are represented in this table: burnout and employee engagement were run in separate } \\
\text { models, and the models were repeated for clinicians and for staff. Adjusted for covariates } \\
\text { and clustering by clinic. Burnout and engagement (likelihood to recommend the clinic) were } \\
\text { tested in separate regression models that included only } 1 \text { of these predictors at a time, along } \\
\text { with the covariates. }\end{array}$} \\
\hline
\end{tabular}


Neither burnout nor employee engagement predicted turnover for staff in the regression models (Table 2). Working full-time (vs part-time), being employed in the university vs the public system, and having worked at the clinical site for longer than 5 years were significantly associated with a lower probability of staff turnover (Supplemental Appendix, available at http://www. AnnFamMed.org/content/17/1/36/supp1/DC1/).

The Hosmer Lemeshow goodness of fit test was nonsignificant for all regressions, indicating acceptable fit of the models.

\section{DISCUSSION}

To our knowledge, this is the first study to investigate whether burnout as measured by the MBI and a common measure of employee engagement predict subsequent documented turnover among clinicians and staff in primary care. We found a high rate of turnover over a 2- to 3-year period among primary care clinicians and staff in the 2 health systems studied. A commonly used measure of burnout, MBI score, significantly predicted clinician but not staff turnover. This pattern was mirrored by a popular "friends and family" measure of employee engagement, which showed a strong trend in predicting turnover among clinicians but not staff.

Estimates of clinician rates of turnover vary widely based on setting. ${ }^{20}$ Although the American Medical Group Association estimated a national annual rate of $6.8 \%$ for physicians and $11.5 \%$ for advanced practice clinicians, ${ }^{21}$ higher rates have been documented in community health centers and underserved settings. ${ }^{20}$ A national study of primary care physicians in the early stage of their careers found that more than one-half left at least 1 practice during a 4 -year period and 20\% left 2 or more employers. ${ }^{12}$ Another study of primary care clinicians and staff in office practices reported $53 \%$ turnover during a 2-year period. ${ }^{22}$ The high level of burnout in our study population is also consistent with those found in nationally representative studies of primary care physicians using the MBI. ${ }^{1}$

High rates of turnover and the high prevalence of burnout and low employee engagement in primary care are all compelling problems. Burnout is a symptom of distress and is associated with poor mental health. ${ }^{23}$ Continuity of care is one of the cardinal principles of primary care, ${ }^{24}$ but it is difficult to maintain in environments with frequent changes in clinician and staff. Turnover is also expensive for health care organizations because of the lost revenue caused by clinician vacancies and the expense of recruiting new personnel, estimated at upward of $\$ 500,000$ per clinician. ${ }^{5,25}$

Despite the prevalence of these problems of high burnout and low employee engagement and wide- spread belief that they beget turnover, there remains little published research evidence of a relationship between burnout or engagement and turnover. Our study, along with another recent study of employed physicians at the Cleveland Clinic, ${ }_{1}^{16}$ adds support to the assertion that burnout and engagement contribute to turnover among clinicians. It does not support, however, the same relationship among primary care staff.

The causes of employee turnover are multifactorial. It may reflect not only a negative "push" of burnout but a positive "pull" of career mobility and opportunities for professional growth. It may also be influenced by varying personal expectations about ideal tenure within an organization, competition among employers for skilled workers, and externalities such as local housing costs, school district quality, and commute times. ${ }^{26}$ These factors other than burnout may be particularly salient for staff.

Our study has several limitations. It was conducted in an urban region with a high cost of living, among employed clinicians and staff. The majority of clinicians reported working part-time, and one-third worked only 1 to 2 half-days per week, compared with a national average of $19 \%$ of physicians working part-time. ${ }^{27}$ This study, however, defines clinical time as only time in clinic seeing their own patients and does not include other clinical time such as that performing inpatient care or precepting residents. The findings may not be generalizable to other practice settings and regions. As in any survey, response bias may influence the validity of the results. Our $90 \%$ response rate is much higher than that reported in most surveys of health care workers, mitigating the potential that nonresponse bias may distort our findings. We relied on clinic leaders to update employment rosters annually at their clinic and had system leaders reconfirm roster data for 2016 to ensure accuracy. We did not have access to employment records maintained by each system's human resources departments; thus, we had no information on the type of employment separation category (eg, retirement, termination, voluntary separation). Clinic leaders, however, reported low rates of involuntary termination and retirement in both systems. There remains considerable variation in measuring burnout ${ }^{28}{ }_{i}$ this study used one of the most common approaches among studies of physicians and residents. ${ }^{29}$ The 2013 and 2014 survey waves did not collect data on respondent sex or age, although tenure at the clinic is to some degree a proxy for age. Inclusion of age and sex might have enhanced the explanatory power of our regression models, but is unlikely to have substantially changed the relationship between burnout or engagement and turnover. We grouped physicians and advanced practice clinicians for analysis. In a larger sample, examination of each group 
separately might yield interesting information about the relationship of work experience and turnover.

In conclusion, the high levels of primary care clinician and staff burnout and turnover observed in this and other studies are concerning. Our findings support the assertion that burnout and low employee engagement contribute to turnover among primary care clinicians, but not among staff. Although reducing burnout among clinicians may help with their retention, health care organizations and policymakers concerned about employee turnover in primary care will need to understand its multifactorial causes to develop effective retention strategies for clinicians and staff.

To read or post commentaries in response to this article, see it online at http://www.AnnFamMed.org/content/17/1/36.

Key words: primary care; burnout; turnover; retention; satisfaction; workforce; workplace engagement; practice-based research

Submitted July 10, 2018; submitted, revised, October 5, 2018; accepted November 1, 2018.

Funding support: Participating health systems funded data collection as part of ongoing quality improvement efforts.

Disclaimer: The article contents are solely the responsibility of the authors and do not necessarily represent views of the funders.

Previous presentations: Presented as a poster at the American Conference on Physician Health; Oct 12-13, 2017; San Francisco, California, and an oral presentation at the North American Primary Care Research Group Annual conference; Nov 17-21, 2017; Montreal, Quebec, Canada.

Acknowledgments: The authors appreciate the partnership of the leadership and staff of the primary care clinics in this study. They also thank Dr Danielle Hessler for consultative advice regarding statistical analysis.

Supplemental Materials: Available at http://www.AnnFamMed. org/content/17/1/36/suppl/DC1/.

\section{References}

1. Shanafelt TD, Hasan O, Dyrbye LN, et al. Changes in burnout and satisfaction with work-life balance in physicians and the general US working population between 2011 and 2014. Mayo Clin Proc. 2015; 90(12):1600-1613.

2. Bodenheimer T, Sinsky C. From triple to quadruple aim: care of the patient requires care of the provider. Ann Fam Med. 2014;12(6):573-576.

3. Sinsky CA, Willard-Grace R, Schutzbank AM, Sinsky TA, Margolius $D$, Bodenheimer $T$. In search of joy in practice: a report of 23 highfunctioning primary care practices. Ann Fam Med. 2013;11(3):272-278.

4. American Medical Association. STEPS Forward. https://edhub.amaassn.org/steps-forward. Accessed Nov 30, 2018.

5. Shanafelt T, Goh J, Sinsky C. The business case for investing in physician well-being. JAMA Intern Med. 2017;177(12):1826-1832.

6. Shanafelt TD, Dyrbye LN, West CP. Addressing physician burnout: the way forward. JAMA. 2017;317(9):901-902.

7. Schutte L. What you don't know can cost you: building a business case for recruitment and retention best practices. J Assoc Staff Physician Recruiters. 2012;19.
8. Maslach C, Jackson S, Leiter M. MBI: Maslach Burnout Inventory Manual. Menlo Park, CA: Mind Garden, Inc; 1996.

9. Williams ES, Skinner AC. Outcomes of physician job satisfaction: a narrative review, implications, and directions for future research. Health Care Manage Rev. 2003;28(2):119-139.

10. Rittenhouse DR, Mertz E, Keane D, Grumbach K. No exit: an evaluation of measures of physician attrition. Health Serv Res. 2004;39(5): 1571-1588.

11. Shanafelt TD, Mungo M, Schmitgen J, et al. Longitudinal study evaluating the association between physician burnout and changes in professional work effort. Mayo Clin Proc. 2016;91(4):422-431.

12. Buchbinder SB, Wilson M, Melick CF, Powe NR. Primary care physician job satisfaction and turnover. Am J Manag Care. 2001;7(7): 701-713.

13. Brewer CS, Chao Y-Y, Colder CR, Kovner CT, Chacko TP. A structural equation model of turnover for a longitudinal survey among early career registered nurses. Int J Nurs Stud. 2015;52(11):1735-1745.

14. Pathman DE, Konrad TR, Williams ES, Scheckler WE, Linzer M, Douglas J; Career Satisfaction Study Group. Physician job satisfaction, dissatisfaction, and turnover. J Fam Pract. 2002;51(7):593.

15. Landon BE, Reschovsky JD, Pham HH, Blumenthal D. Leaving medicine: the consequences of physician dissatisfaction. Med Care. 2006; 44(3):234-242.

16. Windover AK, Martinez K, Mercer MB, Neuendorf K, Boissy A, Rothberg MB. Correlates and outcomes of physician burnout within a large academic medical center. JAMA Intern Med. 2018;178(6):856-858.

17. Shanafelt TD, Balch CM, Bechamps G, et al. Burnout and medical errors among American surgeons. Ann Surg. 2010;251(6):995-1000.

18. Shanafelt TD, Bradley KA, Wipf JE, Back AL. Burnout and selfreported patient care in an internal medicine residency program. Ann Intern Med. 2002;136(5):358-367.

19. Reichheld FF. The one number you need to grow. Harv Bus Rev. 2003:81(12):46-54, 124.

20. Misra-Hebert AD, Kay R, Stoller JK. A review of physician turnover: rates, causes, and consequences. Am J Med Qual. 2004;19(2):56-66

21. Irving F. Physician turnover rate hits all-time high. https://www. healthcarefinancenews.com/news/physician-turnover-rate-hits-alltime-high. Published Mar 29, 2013. Accessed Sep 20, 2018.

22. Ruhe M, Gotler RS, Goodwin MA, Stange KC. Physician and staff turnover in community primary care practice. J Ambul Care Manage. 2004:27(3):242-248.

23. West $C P$, Dyrbye LN, Shanafelt TD. Physician burnout: contributors, consequences and solutions. J Intern Med. 2018;283(6):516-529.

24. Bodenheimer T, Ghorob A, Willard-Grace R, Grumbach K. The 10 building blocks of high-performing primary care. Ann Fam Med. 2014;12(2):166-171.

25. Frenz DA. The staggering costs of physician turnover. Today's Hospitalist. https://www.todayshospitalist.com/staggering-costs-physicianturnover/. Published Aug 2016. Accessed Jun 10, 2018.

26. Mano-Negrin R, Kirschenbaum A. Push and pull factors in medical employees' turnover decisions: the effect of a careerist approach and organizational benefits on the decision to leave the job. Int J Hum Resour Manage. 1999;10(4):689-702.

27. American Medical Group Associates \& Cejka Search. 2007 Physician Retention Survey: Supplemental Edition. https://c.ymcdn.com/sites/ aspr.site-ym.com/resource/resmgr/imported/2013-02_2007-AMGAPhysician-Retention-Survey.pdf. Published 2008. Accessed Jun 10, 2018.

28. Knox M, Willard-Grace R, Huang B, Grumbach K. Maslach Burnout Inventory and a self-defined, single-item burnout measure produce different clinician and staff burnout estimates. J Gen Intern Med. 2018;33(8):1344-1351.

29. Shanafelt TD, Boone S, Tan L, et al. Burnout and satisfaction with work-life balance among US physicians relative to the general US population. Arch Intern Med. 2012;172(18):1377-1385. 